\title{
APROXIMACIÓN JURÍDICA AL CONTENIDO Y ALCANCE DEL NÚCLEO ESENCIAL DEL DERECHO FUNDAMENTAL A LA LIBERTAD INDIVIDUAL EN EL CONSTITUCIONALISMO COLOMBIANO
}

\author{
Cristhian Alexander Pereira Otero ${ }^{* *}$ \\ Recibido: Julio 27 de 2014 \\ Aprobado: Septiembre 14 de 2014
}

\begin{abstract}
RESUMEN
El presente artículo tiene como fin realizar una aproximación conceptual al contenido y alcance del núcleo esencial del derecho a la libertad individual, utilizando algunos elementos teóricos que la dogmática, la filosofía y la jurisprudencia constitucional han desarrollado para ello. Se busca delinear sus fronteras para encontrar su significado y valor, de manera de evitar su transgresión cuando se limite este derecho o colisiona con otros principios constitucionales.
\end{abstract}

Palabras claves: Núcleo esencial, autonomía, libertad individual.

\section{A LEGAL APPROACH TO CONTENTS AND TO THE CORE OF THE FUNDAMENTAL RIGHT TO INDIVIDUAL FREEDOM WITHIN THE COLOMBIAN CONSTITUTIONALISM}

\begin{abstract}
This article focuses on a conceptual approach of the contents and the core of the right to individual freedom. It includes elements that

* Avance de proyecto El núcleo esencial del derecho a la libertad individual - financiado por la Universidad Mariana-Pasto-Colombia.

** Abogado - Universidad de Nariño, Especialista en Derecho Constitucional, Universidad Nacional de Colombia, Especialista en Derecho Contencioso Administrativo y Magister en Derecho Público de la Universidad Externado de Colombia, docente investigador de la Universidad Mariana.Correo electrónico: chepereirapasto@hotmail.com
\end{abstract}


dogmatics, philosophy and constitutional jurisprudence have developed for this purpose. It intends to delineate their borders in order to find out their meaning and value, and to avoid the transgression of the right to individual freedom, when it is limited or it collides with other constitutional principles.

Key words: Core, autonomy, individual freedom.

\section{INTRODUCCIÓN}

La teoría de los Derechos Fundamentales desarrollada a partir de la Constitución de Weimar por Gerhard Anschutz y Richard Thoma (Gomez Serrano, 2009,pág.112) arrancan afirmando la posición nuclear que contiene cada uno de ellos, tales derechos se describen como una esfera, cuya periferia es afectable por la interferencias del poder, mientras que su núcleo duro es refractario a cualquier embate del poder, por estar constituido de elementos esenciales, sin los cuales perdería su identidad; así el núcleo esencial garantiza el objeto del derecho, impidiendo su desaparición, anulación, destrucción o desnaturalizacion (Gavara de Cara,1994, p. 226).

En razón de lo anterior todo derecho fundamental se compone de una zona blanda y una zona dura, la primera susceptible de afectación o limitación y la segunda intocable e irreductible, prohibida de afectarse en todo Estado constitucional de naturaleza garantista de derechos; el núcleo irreductible de los derechos fundamentales se constituye sin duda en una fatigante y ardua tarea en su intelección; dilucidar el contenido esencial, frente al cual todos los poderes del Estado debe limitar su accionar, es una tarea que han emprendido los tribunales constitucionales, en la era del neo constitucionalismo de Europa y América.

En procura de preservar la intangibilidad del núcleo esencial de los derechos fundamentales, La Ley fundamental para la República Federal Alemana (1949) estipuló expresamente en su artículo 19, numeral 2, su intangibilidad al referirse a su contenido así: "En ningún caso se podrá afectar el contenido esencial de un derecho fundamental" en el mismo sentido la Constitución española de 1978, dispuso en su artículo 53, numeral 1, que: "Solo por ley, que en todo caso deberá respetar su contenido esencial, podrá regularse el ejercicio de tales derechos y libertades". A partir de esos postulados normativos, los tribunales 
constitucionales de Alemania y España desarrollaron todo un constructo conceptual denominado: Teoría del núcleo esencial de los derechos fundamentales; el cual ha sido replicado por la jurisprudencia constitucional colombiana en importantes providencias de tutela y de constitucionalidad, siendo la primera, la sentencia C-556 de 1992, en la cual se examinaba la constitucionalidad de algunos decretos legislativos en Estados de excepción.

La tesis del núcleo esencial del derecho fundamental parte de la premisa que todo derecho en su naturaleza cuenta de una zona blanda y una zona dura, la zona blanda es aquella susceptible de afectarse, sin embargo la zona dura, es infranqueable, intocable e irreductible, la cual no se puede afectar, y se denomina núcleo esencial la cual debe ser definida en cada uno de los derechos fundamentales.

El presente artículo pretende construir conceptualmente el núcleo esencial del derecho fundamental a la libertad individual, es decir, determinar su significado, sus límites y fronteras, que tendrá como base algunos apuntes de la doctrina y de la jurisprudencia constitucional colombiana, para que desde allí se extraigan algunos elementos, herramientas y criterios necesarios que se deberán acompañar de los aportes teóricos que la dogmática constitucional ha podido elaborar en la teoría de los derechos fundamentales, acompañado siempre de los esfuerzos importante que realizan autores como: Robert Alexy, Martin Borowsky, Haberle, Jellinek, Perez Luño, entre otros. Lo que permite llegar finalmente a determinar el concepto y alcance del derecho fundamental a la libertad individual (artículo 16 C.N.)

\section{AVANCE}

Una de las preocupaciones más constantes de Bobbio fue intentar esclarecer el significado descriptivo de la libertad, así lo hace saber el profesor Bernal Pulido en un importante estudio que hace sobre el profesor de Turín. La libertad para Bobbio se aborda desde su teoría política en importantes ensayos y obras como: "De la libertad de los modernos comparada con la libertad de los posteriores, Kant y las dos libertades y libertad" (Bernal, 2009, p.127-131) desarrolla tres conceptos de libertad así: Libertad liberal, libertad autonomía y libertad positiva.

Estos tres conceptos de libertad para Bobbio son legítimos y válidos en su propio ámbito que representan estados deseables del hombre, así: 


\section{a. Libertad Liberal}

La libertad liberal es la que se recoge del concepto de la teoría liberal y se define como la esfera de acción que faculta al sujeto para realizar o no ciertas acciones sin ser impedido por otros (familia, sociedad, Estado) en otras palabras, la libertad liberal se compone del conjunto de acciones no impedidas por normas imperativas positivas o negativas y que en términos de Montesquieu es la libertad en hacer todo aquello que permiten las leyes, y que para Hobbes era la situación en que un sujeto actuará según su naturaleza, sin que se lo impidan fuerzas exteriores.

\section{b. La Libertad Autonomía}

Proviene de la teoría democrática y significa la facultad de no obedecer otras normas que las que el sujeto se ha impuesto a sí mismo; y en términos de Bobbio la voluntad libre es la voluntad que se autodetermina.

"Los miembros de un Estado deben gobernarse por sí mismos ya que la verdadera libertad consiste en no hacer depender de nadie más que de uno mismo la reglamentación de la propia conducta" (Bobbio, 2003, pág. 306) Así en virtud de la autonomía el ser humano debe participar directa o indirectamente en la formación de las normas que deberían regular más tarde su conducta en aquella esfera que no está reservada al dominio exclusivo de su jurisdicción individual.

\section{c. Libertad Positiva}

Este concepto de libertad nace de la influencia que las teorías socialistas del siglo XIX hicieron sobre el concepto de libertad, en el entendido de que esta debe abarcar el poder positivo o poder efectivo del Estado para que todo ser humano goce de una auténtica libertad, aquí lo que se señala es como los derechos sociales, como obligaciones positivas a cargo del Estado representan la concreción más adecuada de esta tercera libertad así:

... Si solo existiesen las libertades negativas... todos serian igualmente libres pero no todos tendrían igual poder. Para equiparar a los individuos, reconocidos como personas sociales, también en poder, es necesario que se les reconozcan otros derechos como los derechos sociales, derechos capaces de colocarlos en condición de tener poder de hacer aquello que es libre de hacer (Bobbio, 2003, p. 307). 
Ello se traduce en que el Estado solo tiene sentido en cuanto expresión política de una sociedad conformada por individuos dignos, titulares de derechos, capaces de auto determinarse.

La libertad es sinónimo de democracia y es el estado moderno el que encarna el deber de garantizar el máximo de libertad personal que permita al sujeto elegir y actuar libremente, por eso Eric Fromm establece una relación directamente proporcional de libertad con democracia cuando dice: "El progreso de la democracia consiste en acrecentar realmente la libertad, iniciativa y espontaneidad del individuo, no solo en determinadas cuestiones privadas y espirituales, sino esencialmente en la actividad fundamental de la existencia humana" (From,2000, p.259) El escritor Richard Rorty citado por el Maestro Carlos Gaviria Díaz en la sentencia C-221 de 1994 enseña que en sociedades liberales como la que adopta la carta política colombiana, "El aglutinante social que mantiene unida a la sociedad liberal consiste en poco más que el consenso en cuanto a que lo esencial de la organización social estriba en dar a todos la posibilidad de crearse a sí mismos según sus capacidades". (Corte Constitucional, Sentencia C-221 de 1994) y quien se crea sí mismo es porque vive en una sociedad autónoma y en un estado respetuoso de la autonomía. El Webster's Dictionary que cita el Dr. Szasz define la autonomía como: la cualidad o condición de ser independiente, libre y auto-gobernado y que etimológicamente proviene del griego autos: uno mismo y monos: regla o norma (SZASZ, 2002, p.216) es decir la autonomía es el gobierno propio. Y que según John Stuart Mill es el:

"amor propio... que supone el ejercicio de nuestras capacidades de acuerdo a la propia voluntad "Los tres conceptos del profesor Bobbio a saber: Libertad liberal, autonomía y libertad positiva, se explican así: la primera como la facultad de realizar o no ciertas acciones sin ser impedido por los demás, por la sociedad como un todo orgánico, más sencillamente, por el poder estatal”. (Bobbio, 2003, p.306).

El profesor Carlos Bernal (2009, p.132) lo explica como la facultad que tiene el individuo de contar con una esfera de acción ajena al control del Estado, (Bernal: acciones no impedidas, la esfera de lo permitido, el espacio no regulado por normas imperativas.

Lo que dibuja es un conjunto de límites al ejercicio del poder del Estado. Es decir, que la libertad del ser humano se expresa en la no injerencia de los poderes exteriores del Estado obstaculizado por un exceso de leyes. 
La libertad como autonomía, "se refiere al poder de no obedecer otras normas que las que me he impuesto a mí mismo” (Bobbio,2003, p.307) lo que significa, según lo explica el profesor Bernal que la autonomía indica ser libre, no significa no tener leyes, sino darse leyes a sí mismo. Aumentar el número de acciones regidas por proceso de auto regulación..."Una voluntad libre es una voluntad que se auto determina [...]” (2009, p.133).

"Los miembros de un Estado deben gobernarse por sí mismos, ya que la verdadera libertad consiste en no hacer depender de nadie más que de uno mismo la reglamentación de la propia conducta" (Bobbio, 2003, p. 306) "todo ser humano debe participar directa o indirectamente en la formación de las normas que deberán regular más tarde su conducta en aquella esfera que no está reservada al dominio exclusivo de su jurisdicción individual" (Bobbio, 2003, p.306). Finalmente, la libertad positiva nace de la influencia que las teorías socialistas del siglo XIX hicieran al concepto de libertad, cuando hacen relación a la suficiente capacidad económica para satisfacer algunas necesidades fundamentales de la vida material y espiritual, sin las cuales la libertad liberal sería vacía y la libertad democrática sería estéril, en términos precisos del maestro Bobbio sería:

(...) si solo existiesen las libertades negativas (...) todos serian igualmente libres pero no todos tendrían igual poder. Para equiparar a los individuos, reconocidos como personas sociales, también en poder, es necesario que se les reconozcan otros derechos como los derechos sociales, derechos capaces de colocarlos en condición de tener el poder de hacer aquello que es libre hacer. (Bobbio, 2003, p.137).

En la filosofía política, junto al concepto de libertad positiva siempre ha existido el de la libertad negativa.

De acuerdo con este último concepto, el individuo no solo es libre de hacer lo razonable o necesario, sino libre de hacer o dejar de hacer lo que quiera, sin intervenciones externas provenientes del Estado o de otros individuos (Berlín, 1996, p.200). Se trata de la libertad de arbitrio citada por Kant, al definirse como independencia de la determinación, que permite que la libertad jurídica como libertad negativa, no elimina la libertad positiva, sino que la reserva como creyente, como laico o como sujeto ético, ámbito reservado al individuo, un espacio para la toma de sus decisiones vitales; se trata de una libertad negativa, porque en su ámbito se niega el poder externo, la heteronomía. 
De esta manera importantes sentencias de tutela y de constitucionalidad han estudiado el tema de la libertad para determinar su posible contenido, inspirado muchas veces en posiciones de filosofía política, que logran enriquecer su contenido y fijar criterios para significar su contenido esencial, desconocido aún. Polémicas sentencias irreverentes, delinean la frontera de la libertad y se sustentan desde la libertad, tales como las establecen la interrupción voluntaria del embarazo desde la libertad procreativa de la mujer (C- 133 de 1994, C- 013 de 1997, C-657 de 2001, C-355 de 2006 T-988 de 2007, T- 209 de 2008 y T946 de 2008, T-513 de 1995 ,) las que construyen el derecho a morir dignamente y a renunciar tratamientos en Testigos de Jehová desde la autonomía (C- 239 de 1997, T-411 de 1994, T-474 de 1996) entre otras. Son estas, algunas providencias en las que la tensión entre otros principios constitucionales logran bordear los límites del Estado frente al derecho fundamental de la libertad, ese núcleo esencial, resultado del descubrimiento al límite del límite.

El tribunal constitucional alemán ha definido el núcleo esencial de los derechos fundamentales como lo intangible del derecho fundamental, límite absoluto, extremo.

Este fenómeno es replicado por la Corte Constitucional colombiana y desarrollado en algunos derechos fundamentales, tales como la petición, la libertad de cultos entre otros; sin embargo se desconoce su concepto frente a la libertad individual, lo cual lleva al jurista y filósofo alemán Haberle a entender que los derechos fundamentales por definición no son limitables; en su criterio, lo que se realiza es la determinación del contenido, mediante la ponderación entre el fin de la intervención y la drasticidad de la restricción; y asimila, por tanto, el contenido del derecho a su protección definitiva.

La jurisprudencia del tribunal constitucional alemán retoma los diversos elementos de estos criterios y asume que los derechos fundamentales no son ilimitados; por lo cual pueden ser objeto de restricciones y limitaciones justificadas por la propia Constitución, cuando los derechos de diferentes personas colisionan entre sí, y cuando se hace necesario proteger otros valores jurídicos con rango constitucional.

El contenido esencial del derecho fundamental a la libertad, cuando se trata de decidir la muerte de su titular, la renuncia a tratamientos, la escogencia de profesión, oficio, la forma de vestir y la defensa de las convicciones personales, la libertad de informar y expresar sigue siendo 
objeto de cuestionamiento y auscultar el contenido de la autonomía del individuo frente a otros derechos en los cuales colisiona, es el motivo de esta ponencia, justificada en la respuesta obligatoria que la academia debehacer.

Este vital cuestionamiento que inquieta a juristas y académicos puede ser resuelto al identificar las fronteras trazadas por otros derechos que en determinados casos la afecten, lo cual serviría para lograr determinar el núcleo esencial de la libertad individual.

Los núcleos esenciales de los derechos fundamentales deben responder a un contenido o significado, que son fronteras de no intervención para el Estado y los particulares; los criterios y elementos para descubrirlos dependen de la elaboración que realicen la jurisprudencia y la doctrina sobre cada uno de ellos; para el caso en cuestión es un enigma jurídico que pretendemos encontrar; la ley fundamental de Bonn estableció que en ningún caso se podrá afectar el contenido esencial de un derecho fundamental; en el mismo sentido la Constitución Española de 1978, dispuso en su artículo 53 que: “...[s]olo por ley, que en todo caso deberá respetar su contenido esencial, podrá regularse el ejercicio de tales derechos y libertades"

Sin embargo, el primer teórico que aborda el tema del núcleo esencial es el filósofo y jurista alemán Haberle, quien señala que los derechos fundamentales por definición no son limitables (Gómez, 2008, p.133) lo que se realiza es la determinación del contenido, mediante la ponderación entre el fin de la intervención y la drasticidad de la restricción; asimilando, por tanto, el contenido del derecho a su protección definitiva.

El profesor Sánchez Gil sustenta dos teorías sobre derechos fundamentales, una absoluta y otra relativa. La primera considera que el derecho fundamental en su ámbito normativo se compone de círculos concéntricos: uno interior fijo e inmutable del derecho llamado núcleo esencial; y otro ubicado en la sección circunferencial exterior como la parte accesoria o contingente de los mismos.

Así, el núcleo definido como la parte intocable de estos y cualquier afectación a su respeto sería ilícita, en cambio en la parte contingente se pueden establecer las restricciones y limitaciones que se consideren necesarias y justificadas. 
Por otro lado la teoría relativa entiende que el contenido esencial de los derechos fundamentales no es preestablecido y fijo, sino determinable solo casuísticamente en atención de las circunstancias del caso y luego de ponderarse los beneficios y perjuicios que se produzcan en él, tanto para el derecho afectado como para el bien protegido a través de su limitación.

En ese orden de ideas, el núcleo esencial de un derecho fundamental es resguardado indirectamente por el principio constitucional de ponderación del fin legítimo a alcanzar frente a la limitación del derecho fundamental.

Así por ejemplo, el ejercicio efectivo del derecho de petición supone el derecho a obtener una pronta respuesta del asunto solicitado, que no implica que sea esta favorable; según esta tesis, los criterios que sirven de apoyo para determinar el contenido esencial de un derecho fundamental son principalmente dos: i) hacen parte del núcleo esencial las características y facultades que identifican el derecho, sin las cuales se desnaturalizaría y, ii) integran el núcleo esas atribuciones que permiten su ejercicio, de tal forma que al limitarlas el derecho fundamental se hace impracticable.

Esto explica entonces por qué el constituyente exigió que la regulación del núcleo esencial de los derechos fundamentales esté sometida a la reserva de ley estatutaria, pues es evidente que la brecha que separa la limitación legítima del núcleo y su anulación (que por ese hecho resultaría contraria a la Constitución) no solo es muy sensible, sino que además requiere un debate legislativo responsable, consciente y fundamentado que soporte la decisión.

El profesor Gómez Serrano una vez más nos indica que el Tribunal Constitucional alemán ha asumido la concepción del núcleo esencial e intangible del derecho fundamental, refiriéndose indistintamente a límite absoluto, límite extremo, último ámbito intangible, pero sin adscribirse de manera exclusiva a ninguna teoría sino más bien, combinnado sus elementos, para poder demarcar las intervenciones legislativas abusivas, entendiendo que al traspasar sus límites, se disolvería la sustancia del Derecho, a cuyo efecto señala que hay un límite absoluto, cuya transgresión afectaría al contenido esencial.

El tribunal constitucional español, sin matricularse a una teoría en especial, ha indicado que la libertad del legislador no puede afectar el 
contenido esencial de los derechos fundamentales, rastreándolos a partir de los intereses jurídicamente protegidos por la naturaleza específica de cada derecho. (Gómez, 2009, p.116).

Ahora bien, el alcance del derecho a la libertad individual comienza desde las decisiones de Cortes norteamericanas que tumbaron normas de establecimientos educativos que restringían el uso del bigote, el cabello largo, etc., sustentadas en derechos de libertad de expresión e intimidad que sirvieron de soporte jurídico para sentar precedente de un derecho del libre desarrollo a la personalidad que no existía hasta entonces; hasta la construcción de este derecho en casos de homosexualidad en los Estados unidos y Europa; en Alemania, la corte de distrito de Berlín, negó a una persona el derecho a exigir de la autoridad administrativa pertinente el cambio de sexo de masculino a femenino, en los papeles de identificación; la situación era tal que el transexual luego de un tratamiento hormonal y quirúrgico cambió su sexo de hombre a mujer; o también el caso en el cual otra corte alemana prohibió a un padre colocar el nombre de Marco Bernardo Antonieta a su hijo, pues a juicio de la corte ello generaba confusión sobre el sexo y la personalidad que terminaría afectando su dignidad y el desarrollo de su personalidad.

Estos ejemplos trascurridos en diferentes espacios y tiempos de la vida del derecho a la autonomía la enseña el profesor Manuel Cepeda defensor del espíritu constituyente que reconoció al ser humano la capacidad natural de regular por sí mismo sus actos, como agente racional y responsable de todos los escogimientos y opciones que le atañen, sin ningún impedimento que lo constriña para no disponer de su vida conforme a su voluntad o libre determinación. (Cepeda, 1997, p.149).

Ahora bien, en Colombia el articulo 16 superior que consagra el derecho fundamental al libre desarrollo de la personalidad se constituye en la cláusula general de la libertad, que no es nada más que la consideración de la persona como sujeto ético, capaz de gobernarse y determinar sus fines y destinos, el ser humano es sujeto moral, así lo indica la Corte: "Cuando el Estado resuelve reconocer la autonomía de la persona, lo que ha decidido, ni más ni menos, es constatar el ámbito que le corresponde como sujeto ético: dejarla que decida sobre lo más radicalmente humano, sobre lo bueno y lo malo, sobre el sentido de su existencia." (Corte Constitucional, Sentencia C-221 de 1994). 
Esa libertad decisoria del sujeto capaz de auto-determinarse se descifra "en que los asuntos que solo a la persona atañen, solo por ella deben ser decididos... Decidir por ella es arrebatarle brutalmente su condición ética, reducirla a la condición de objeto, cosificarla, convertirla en medio para los fines que por fuera de ella se eligen. " (Corte Constitucional, Sentencia C-221 de 1994).

En ese orden de ideas al Estado le es prohibido invadir la esfera íntima de la libertad individual pues no puede imponer normas jurídicas conmigo mismo porque estaría violando las fronteras que ontológicamente le están vedadas que son los límites del ejercicio de la libertad que es propio de la persona.

El profesor Cepeda entiende que el derecho fundamental a la libertad individual se estructura en acciones negativas y positivas, las primeras entendidas como: "... la libertad individual para tomar decisiones que concierne y afectan el desarrollo de la personalidad y la libertad para emprender las actividades individuales o sociales que le permitan a la persona proyectar su visión de sí misma." (1997, p.146).

Es decir como prohibición del Estado y terceros frente al individuo. (Cepeda, 1997, p.146) Al constituirse como límite a la autoridad, el sentido positivo se deduce como la facultad entregada al individuo para que decida su forma de ser y destino trazado en la sociedad, con la garantía que tiene el sujeto para respetar la esfera íntima de la decisión propia que no está subordinada al ámbito de libertad colectiva.

Existe una zona común en la cual impera el derecho al imponerme deberes con la sociedad. "El legislador puede prescribirme la forma en que debo comportarme con otros, pero no la forma en que debo comportarme conmigo mismo, en la medida de que mi conducta no interfiera con la órbita de acción de nadie" (Corte Constitucional, Sentencia C- 221 de 1994) y una zona que es propia de cada persona: Es el derecho del individuo, así la corte interpreta partiendo desde las características definitorias del derecho y la moral, donde el primero es heterónomo, bilateral y de coacción por parte del Estado y el segundo es autónomo, unilateral y ausente de coacción.

Para ser autónomo es necesario estar libre; el profesor Hofman, quien cita a Kant, indica que la libertad es independencia, así: “(...) de la combinación de libertad e igualdad en el sentido de libertad igual debe seguir que solo puede ser colegislador quien sea su 'propio amo' o sea que 
no dependa de ninguna otra persona" (Hofmann, 2002, pág. 206). Por tanto la independencia que se tiene cuando se es autónomo nace de la libertad de diseñar el propio destino y el desarrollo de la existencia; como un fin en sí mismo y no como medio para alcanzar los fines, la Corte indica que la primera consecuencia que se deriva de la autonomía consiste en que es la propia persona y nadie por ella quien debe darle sentido a su existencia y, en armonía con ella, es así como los asuntos que solo a la persona atañen, solo por ella deben ser decididos, decidir por ella es arrebatarle brutalmente su condición ética, reducirla a la condición de objeto, cosificarla, convertirla en medio para los fines que por fuera de ella se eligen, la existencia de ese derecho reside en la autodeterminación de la persona, es decir, que ella sea propietaria de sí misma y de sus actos reflejando una imagen digna para ella y para la sociedad.

Por eso el Estado colombiano no puede asumirse dueño del destino de cada quien, de ahí se deriva el respeto de su autonomía para ser tratado como sujeto y no como objeto. El libre desarrollo de la personalidad traduce la posibilidad de adoptar un modo de vida de acuerdo con sus propios intereses, convicciones, inclinaciones, y deseos en el marco del respeto de los derechos de los demás y el orden jurídico. "De esta forma podríamos decir que ese derecho de opción comprende la libertad y la independencia del individuo para gobernar su propia existencia y para construir un modelo de personalidad de acuerdo a su conciencia y con el único límite de no causar daño social" (Corte Constitucional, Sentencia 221 de 1997) Así las cosas el derecho al libre desarrollo de la personalidad es libertad individual para tomar por sí sola decisiones que conciernen a la esfera de su vida privada (Corte Cosntitucional:1993,21) donde nadie más gobierna.

En ese orden de ideas resultaría contradictorio garantizar un derecho de autonomía si se restringe la libertad de decidir o se impone tácitamente una forma de comportamiento, conducta o sentir especial, propio del Estado o del gobierno en turno; la ventaja del derecho es la elección libre y no camufladamente impuesta o no supuestamente libre. Ahora bien, cuando el Estado es quien se abroga la potestad absoluta de conocer mejor los intereses de cada individuo, la Corte ha contemplado cómo el llamado truco ilusorio que empuña el Estado a través de su legislador para determinar su decisión y no la del sujeto, Dworkin la define como "las políticas de protección a los intereses de la propia persona, que son constitucionalmente admisibles, denominadas por algunos sectores de la filosofía ética como "paternalismo"." (Dworkin,1990, p.196) e 
igualmente advertida $\mathrm{p}$ or la Corte al manifestar que cuando el Estado se encamina por la vía benévola del paternalismo se puede llegar a la negación de la libertad individual, ya que se estaría instaurando un Estado protector de sus súbditos, que conoce mejor que estos lo que conviene a sus propios intereses y hace entonces obligatorio lo que para una persona libre sería opcional, Es decir tratar a sus ciudadanos como menores de edad, incapaces de decidir por sí solos; donde el Estado es el único capaz de dirigir sus vidas; la Corte al tratar el paternalismo del Estado (Corte Constitucional:1997,42) lo identifica como el abuso al amparo de la tutela cuando infiere en la autonomía individual para anularlo.

"La victoria de la libertad es solamente posible si la democracia llega a constituir una sociedad en la que el individuo, su desarrollo y felicidad constituyan el fin y el propósito de la cultura en la que la vida no necesite justificarse por el éxito o por cualquier otra cosa, y en la que el individuo no se vea subordinado ni sea objeto de manipulaciones por parte de ningún otro poder exterior a el mismo, ya del Estado o la organización económica(...)" (Fromm, 2000, p. 257).

La sentencia C-309 de 1997 sentó la diferencia entre las medidas de protección y las medidas perfeccionistas; las primeras propias de los Estados garantistas que tienen como fundamento la dignidad humana, y las segundas correspondientes a los Estados dictatoriales o totalitarios que imponen modelos de virtud a través de la represión; la providencia constitucional estudiada por el alto tribunal pretendió determinar el examen de constitucionalidad de la multa por no usar el cinturón de seguridad para identificar si es una medida de protección del derecho a la vida y a la integridad personal, o por el contrario es una medida perfeccionista que impone modelos de virtud y que vulnera el derecho al libre desarrollo de la personalidad.

Existen como lo anota HAKSAR, algunas medidas e instituciones paternalistas que tienen aceptación y justificación, como son: la obligatoriedad de la educación primaria, el cumplimiento de las leyes laborales, la vacunación obligatoria, la prohibición del duelo, en la obligatoriedad del cinturón de seguridad en automóviles, entre otros, pues como lo indica el Maestro argentino Carlos Santiago Nino, son: "Un paternalismo no perfeccionista estaría dirigido a proteger a los individuos contra actos y omisiones de ellos mismos que afectan su propio interés subjetivo o las condiciones que los hacen posibles"(Nino, 1984, p.142) de tal manera que un Estado paternalista es aquel que limita. 


\section{CONCLUSIONES}

Un Estado puede favorecer ciertos estilos de vida, pero no prohibir modelos de vida; el Estado puede disuadir, desestimular pero nunca irrespetarlos, la justificación solo es válida cuando se coloca en riesgo el derecho de terceros; al respecto el maestro Carlos Santiago Nino considera que:

(...) la concepción opuesta al principio de autonomía tal y como lo he presentado se suele denominar 'perfeccionismo'. Esta concepción sostiene que lo que es bueno para un individuo o lo que satisface sus intereses es independiente de sus propios deseos o de su elección de forma de vida y que el Estado puede a través de distintos medios dar preferencia a aquellos intereses y planes de vida que son objetivamente mejores. (Nino, 1984, p.143).

Es decir que el contenido del derecho a la autonomía supone la neutralización de la preferencias externas acerca de cómo los demás deben vivir, según lo determine el Estado; así las cosas las medidas paternalistas determinarán cuándo estamos frente a una vulneración del núcleo esencial, pues el referente indicador será si la medida que afecta la libertad individual es paternalista o protectora.

Cualquier limitación al libre desarrollo de la personalidad afectará su núcleo esencial cuando la medida que la limita o afecta impide en forma irrazonable, alcanzar o perseguir aspiraciones legítimas en su vida o valorar y escoger libremente las opciones y circunstancias que le dan sentido a su existencia, y permiten su realización como ser humano; tal restricción es Iusfundamentalmente prohibida, cuando trasgrede "opciones de vida" que por definición son libres, esa es una aproximación al contenido y sentido del núcleo esencial de la libertad individual.

\section{REFERENCIAS BIBLIOGRÁFICAS}

Alemania. Ley Fundamental para la República Alemana (1949). Recuperado de http://ocw.um.es/cc.-juridicas/derecho-internacionalpublico-1/ejercicios-proyectos-y-casos-1/capitulo4/documento-20constitucion-de-alemania.pdf. 
Berlín, I. (1996). Dos conceptos de libertad. En: Cuatro ensayos sobre la libertad. Madrid: Alianza Editorial.

Bernal Pulido, C. (2009). El Neoconstitucionalismo y la normatividad del derecho. Bogotá: Universidad Externado de Colombia.

Bobbio, N. (2003). Teoría General de la Política. Madrid: Trotta.

Cepeda, M. (1997). Los Derechos Fundamentales en La Constitución de 1991. Bogotá: Editorial Temis.

Colombia Corte Constitucional. Sentencia T-493 del 28 de octubre de 1993. (Magistrado Ponente: Antonio Barrera Carbonell)

Colombia. Corte Constitucional. Sentencia C-221 del 5 de mayo de 1994 (Magistrado Ponente: Carlos Gaviria Díaz)

Colombia. Corte Constitucional. Sentencia C-309 del 25 de junio de 1997 (Magistrado Ponente: Alejandro Martínez Caballero)

Dworkin, G. (1990). El paternalismo. En: Derecho y moral. Barcelona: Ariel.

España. Constitución Política (1978). Recuperado de http://www.congreso.es/consti/constitucion/indice/

Fromm, E. (2000). El Miedo a la Libertad. Barcelona: Paidós.

Gavara de Cara, J. (1994). Derechos fundamentales y desarrollo legislativo. Madrid: Centro de Estudios Constitucionales.

Gómez Serrano, L. (2009). Teoría de los Derechos Fundamentales. Bogotá: Ediciones Doctrina y Ley.

Hofmann, H. (2002). Filosofia del Derecho y del Estado. Bogotá: Universidad Externado de Colombia.

Nino, C. (1984). Ética y Derechos Humanos. Buenos Aires: Paidós.

Szasz, T. (2002). Libertad Fatal, Ética y Política del Suicidio. Barcelona: Paidós Ibérica. 